\title{
Técnicas de pulverização e imersão com distintos desinfetantes sobre ovos incubáveis
}

\author{
Immersion and pulverization techniques with different disinfectants above \\ hatchin eggs
}

\author{
Huldo Colares Cony ${ }^{I^{*}}$ Sergio Luiz Vieira ${ }^{\mathrm{II}}$ Josemar Berres $^{\mathrm{I}}$ Hirã Azevedo Gomes ${ }^{\mathrm{I}}$ \\ Jorge Luis Bernardon Coneglian ${ }^{\mathrm{I}}$ Dimitri Moreira de Freitas ${ }^{\mathrm{III}}$
}

\section{RESUMO}

Foram conduzidos dois experimentos com o objetivo de avaliar a eficiência de diferentes princípios ativos desinfetantes e dois métodos de desinfecção de ovos. No primeiro experimento, as desinfecções foram realizadas por pulverização, enquanto que no segundo foram feitas por imersão, em granja de reprodutoras pesadas imediatamente após a postura. Os experimentos foram constituídos por um tratamento sem desinfecção e outros seis utilizando soluções desinfetantes: fenol sintético (1040ppm), digluconato de clorexidina (200ppm), amônia quaternária (800ppm), amônia quaternária (400ppm) + uréia (600ppm), amônia quaternária (130ppm) + glutaraldeído (370ppm) e formaldeído $\left(7,7 \mathrm{~g} \mathrm{~m}^{-3}\right)$. Em cada experimento houve tratamentos-controle com fumigação (formaldeído) e sem desinfecção alguma. Após a desinfecção, 40 ovos por tratamento foram avaliados para presença de mesófilos totais, bolores e leveduras, coliformes totais, Pseudomonas sp e Aspergillus sp. Foi conduzido embriodiagnóstico nos ovos não eclodidos para determinação do período da mortalidade embrionária, da contaminação interior dos ovos, tendo sido determinado o nascimento de pintos impróprios para a criação e a eclodibilidade. No experimento em que os ovos foram desinfetados por pulverização, a associação entre amônia e glutaraldeído apresentou maior contaminação para mesófilos totais em relação aos demais tratamentos, à exceção do tratamento com fenol sintético, que apresentou contaminação semelhante a todos. Não foram detectadas diferenças entre os tratamentos para bolores e leveduras, coliformes totais, Pseudomonas sp e Aspergillus sp e, tampouco, entre os resultados de embriodiagnóstico. No experimento em que os ovos foram desinfetados por meio de imersão, foi verificada maior contaminação por mesófilos totais nos ovos não-desinfetados em relação aos desinfetados com os diferentes princípios ativos. Os ovos sem desinfecção também apresentaram maior contaminação por coliformes totais em relação aos tratados com amônia e uréia, sendo os demais tratamentos similares a todos. A análise de contaminação por bolores e leveduras, Pseudomonas sp e Aspergillus sp mostrou resultados similares entre os tratamentos. Os ovos desinfetados com formaldeído tiveram maior mortalidade embrionária, no período de quatro a sete dias, em relação àqueles desinfetados com amônia quaternária, sendo os outros tratamentos similares a todos. De modo geral, os desinfetantes estudados apresentaram capacidade de ação na redução da contaminação microbiana da casca de ovos incubáveis. Todos os desinfetantes também demonstraram ser seguros sob o ponto de vista de sobrevivência dos embriões, sem grandes restrições.

Palavras-chave: desinfecção, desinfetantes, eclodibilidade, mortalidade embrionária, ovos.

\section{ABSTRACT}

Two experiments were conducted with the objective of evaluating different active compounds and methods of egg disinfection. In the first experiment, disinfection was done through spray whereas in the second it was done using immersion. Disinfections were performed at breeder house immediately after laying. In both experiments there were five treatments using the following disinfection solutions for each method: synthetic phenol (1040ppm), chlorexidine digluconate (200ppm), quaternary ammonium (800ppm), quaternary ammonium (400ppm) + urea (600ppm), quaternary ammonium (130ppm) + glutaraldehyde (370ppm). In both experiments there were a control treatment without disinfection and another using disinfection using fumigation with formaldehyde $\left(7.7 \mathrm{gm}^{-3}\right)$. After the disinfection procedures, forty eggs per treatment were evaluated for presence of total mesophiles, mould and yeast, total coliforms, Pseudomonas sp and Aspergillus sp. Embryo diagnosis was driven in no hatched eggs, for determination of embryo mortality period, interior contamination, and it was determined the birth of

IPrograma de Pós-graduação em Zootecnia, Departamento de Zootecnia, Universidade Federal do Rio Grande do Sul (UFRGS). Av. Bento Gonçalves, 7712, Agronomia, 91540-000, Porto Alegre, RS, Brasil. E-mail: huldo.cony@eleva.com.br.*Autor para correspondência.

"Departamento de Zootecnia, UFRGS, Porto Alegre, RS, Brasil.

"I'Faculdade de Medicina Veterinária, UFRGS, Porto Alegre, RS, Brasil. 
inappropriate chicks for rear and hatchability. In the experiment in that eggs were disinfected by pulverization, the association between ammonia and glutaraldehyde presented higher contamination for total mesophiles in relation to other treatments, with exception of synthetic phenol treatment, which presented similar contamination to all. Differences were not detected among treatments for mold and yeast, total coliforms, Pseudomonas sp and Aspergillus sp, and for embryo diagnosis results. In experiment in that eggs were disinfected through immersion, higher contamination was verified to total mesophiles in eggs no disinfected in relation to disinfected with the different active components. Eggs without disinfection also presented larger contamination for total coliforms in relation to ammonia and urea treatment, being similar to all other treatments. The analysis of mold and yeast contamination, Pseudomonas sp and Aspergillus sp showed similar results among treatments. Eggs disinfected with formaldehyde had higher embryo mortality, in the period from 4 to 7 days, in relation to those disinfected with quaternary ammonia, being other treatments similar to all. In general, the studied disinfectants presented action capacity in the reduction of microbial contamination of incubated eggs. All disinfectants also demonstrated to be safe to survival of the embryos, without great restrictions.

Key words: disinfectants, disinfection, eggs, embryo mortality, hatchability.

\section{INTRODUÇÃO}

A qualidade dos ovos incubáveis é fundamental para obtenção de altos níveis de eclosão. As práticas destinadas à manutenção desta qualidade requerem coletas freqüentes, limpeza e desinfecção adequadas, uma vez que a microbiota bacteriana existente na superfície da casca pode infectar e causar mortalidade de embriões e pintos recém-nascidos. Durante o processo de resfriamento dos ovos, há um fluxo natural de ar da superfície para o interior dos ovos que carreia contaminantes por meio dos poros da casca (SCOTT \& SWETNAM, 1993). Dessa forma, os ovos devem sofrer desinfecção o mais rapidamente possível após a postura por meio de métodos e com compostos adequados (MAULDIN, 2002; SESTI, 2005).

Os métodos de desinfecção de ovos comumente utilizados na indústria são a fumigação (volatilização de um desinfetante), a pulverização e a imersão. WHISTLER \& SHELDON (1989) avaliaram a contagem microbiológica e a eclodibilidade de ovos fumigados com formaldeído e ozônio, evidenciando mortalidade excessiva no grupo desinfetado com ozônio. SHELDON \& BRAKE (1991) detectaram menor mortalidade embrionária tardia em ovos pulverizados com peróxido de hidrogênio em relação a ovos fumigados com formol. BRAKE \& SHELDON (1990) encontraram redução de $98 \%$ da contaminação microbiológica da casca de ovos pulverizados com solução de amônia quaternária. Processos de desinfecção por imersão vêm sendo propostos, utilizando temperaturas da água entre 35 e $42^{\circ} \mathrm{C}$ (PROUDFOOT et al., 1985; DONASSOLO \& NETO, 2004). DONASSOLO \& NETO (2004) compararam eclodibilidade e contaminação microbiológica na casca de ovos imersos em solução de fenóis sintéticos e ovos fumigados com formol e verificaram melhores resultados no grupo imerso com fenol.

Avaliações de eficiência entre métodos de desinfecção são raros na literatura, o que limita a adoção daquele método mais eficiente. Da mesma forma, em relação às diversas substâncias químicas disponíveis para uso como desinfetante, são limitadas as avaliações para utilização em ovos incubáveis. O objetivo deste trabalho foi avaliar o uso de desinfetantes usualmente empregados para desinfecção de ovos por meio dos métodos de pulverização e imersão.

\section{MATERIAL E MÉTODOS}

Dois experimentos foram conduzidos separadamente, sendo que a coleta e a desinfecção dos ovos forma realizadas em granja de reprodutoras pesadas. Os ovos foram incubados no Incubatório Experimental do Departamento de Zootecnia da Universidade Federal do Rio Grande do Sul, na cidade de Porto Alegre, RS. De acordo com as normas vigentes nesta instituição, não houve necessidade de submissão do trabalho à comissão de ética.

\section{Experimento 1}

Foram utilizados ovos de matrizes pesadas da linhagem ISA Vedette com 42 semanas de idade. Estes foram desinfetados por meio do sistema de pulverização com máquina costal, contendo solução desinfetante a temperatura ambiente. Os tratamentos foram compostos por fenol sintético (200ppm (ortofenilfenol, $12 \mathrm{~mL}$; orto-benzil paraclorofenol, $10 \mathrm{~mL}$; paraterceário amilfenol, $4 \mathrm{~mL}$; veículo, $74 \mathrm{~mL}$ )), digluconato de clorexidina (200ppm (digluconato de clorexidina, $20 \mathrm{~mL}$; veículo, $80 \mathrm{~mL}$ )), amônia quaternária (800ppm (cloreto de alquil dimetil benzil amônio, $40 \mathrm{~mL}$; veículo, 60mL)), amônia (400ppm) associada à uréia (600ppm) (cloreto de alquil dimetil benzil amônio, 40g; uréia, 60g), amônia (130ppm) associada à glutaraldeído (370ppm) (cloreto de alquil dimetil benzil amônio, 13mL; glutaraldeído, 37mL; veículo, 50mL). Foi usado um tratamento controle desinfetado por meio de fumigação com formaldeído (paraformaldeído, 91g; veículo, 9g) volatilizado sobre uma chapa metálica em câmara de desinfecção (ambiente controlado), na dosagem de 7,7g $\mathrm{m}^{-3}$ por $15 \mathrm{~min}$ e outro sem desinfecção. Os tratamentos tiveram 11 repetições de 45 ovos. Foram utilizados ovos 
livres de excretas e deformações. Os ovos foram coletados apenas em ninhos, sendo desinfetados imediatamente após a postura.

Após a desinfecção, foram coletados 40 ovos por tratamento e enviados ao laboratório de microbiologia para análise de contaminação da casca por mesófilos totais, bolores e leveduras, coliformes totais, Pseudomonas sp e Aspergillus sp. Foi realizado um esfregaço na casca dos ovos com gaze estéril embebida em peptona $0,1 \%$, clara e gema, na proporção de 1:9. Foi realizada homogeneização e diluição até $10^{-5}$. Todos os tratamentos foram analisados conforme métodos microbiológicos descritos na Instrução Normativa 62 do MAPA(2003).

Os ovos destinados à incubação foram armazenados no incubatório durante três dias sob temperatura média de $18^{\circ} \mathrm{C}$ e umidade relativa de $65 \%$. Estes foram alojados em incubadora experimental de estágio único com capacidade para 3.600 ovos. Seguindo as determinações de McQUOID (2000), a temperatura da incubadora foi regulada a $37,7^{\circ} \mathrm{C}$ até o $10^{\circ}$ dia de incubação, $37,5^{\circ} \mathrm{C}$ do $11^{\circ}$ ao $12^{\circ}, 37,3^{\circ} \mathrm{C}$ do $13^{\circ}$ ao $15^{\circ}$ e $37,1^{\circ} \mathrm{C}$ do $15^{\circ}$ dia de incubação até o fim da eclosão, no nascedouro. A umidade relativa foi de $60 \%$ do $1^{\circ}$ ao $18^{\circ}$ dia e de $70 \%$, após a transferência para o nascedouro, até o nascimento. Após a remoção dos pintos, ao final da eclosão, foi realizado embriodiagnóstico nos ovos restantes para avaliar o percentual de eclodibilidade sobre os ovos férteis, mortalidade embrionária de um a três, quatro a sete, oito a 14 e 15 a 21 dias de incubação, ovos contaminados e pintos impróprios à criação.

\section{Experimento 2}

Foram utilizados os mesmos princípios ativos adotados no experimento 1 . Os ovos analisados eram provenienntes de reprodutoras Ross 308 com 49 semanas de idade. A imersão dos ovos foi feita em soluções desinfetantes a uma temperatura média de $36^{\circ} \mathrm{C}$, utilizando caixas de imersão com resistência elétrica e termostato. Os ovos foram imersos por um período de 15 s e acondicionados sobre a lateral da caixa de imersão para que o excesso de solução desinfetante retornasse para o interior da caixa. O manejo da incubação, assim como as variáveis analisadas no embriodiagnóstico, foram similares aos do experimento 1.

Em ambos os experimentos foi utilizado delineamento em blocos casualizados, sendo que o bloco foi a altura do carrinho (andar) em que os ovos foram dispostos dentro da máquina de incubação. Os resultados obtidos em percentual foram submetidos à transformação para arco seno para análise estatística. As variáveis que apresentaram diferença estatística no teste $\mathrm{F}$ foram submetidas ao teste de Tukey $(\mathrm{P}=0,05)$.

\section{RESULTADOS E DISCUSSÃO}

\section{Experimento 1}

Na tabela 1 podem ser observados os níveis de contaminação por diferentes microrganismos em ovos submetidos a diferentes desinfetantes aplicados por meio do método de pulverização. A associação entre amônia e glutaraldeído apresentou maior contaminação para mesófilos totais em relação aos demais tratamentos, à exceção do tratamento com fenol sintético, que apresentou contaminação semelhante a todos os tratamentos. Não foram detectadas diferenças entre os tratamentos para bolores e leveduras, coliformes totais, Pseudomonas sp e Aspergillus sp e tampouco entre os resultados de embriodiagnóstico.

Na tabela 2 são apresentados os resultados do embriodiagnóstico de ovos não eclodidos

Tabela 1 - Análise microbiológica das cascas de ovos submetidos à desinfecção por pulverização com diferentes princípios ativos antes da incubação (experimento 1).

\begin{tabular}{|c|c|c|c|c|c|}
\hline \multirow{2}{*}{ Tratamentos } & \multirow[b]{2}{*}{ Mesófilos totais } & \multirow[b]{2}{*}{ Bolores e leveduras } & \multirow[b]{2}{*}{ Coliformes totais } & \multirow[b]{2}{*}{ Pseudomonas sp } & \multirow[b]{2}{*}{ Aspergillus sp } \\
\hline & & & & & \\
\hline Controle & $51,3^{b}$ & 0,0 & 16,3 & 0,0 & 0,0 \\
\hline Amônia & $7,9^{\mathrm{b}}$ & 0,0 & 0,8 & 0,0 & 0,0 \\
\hline Amônia + uréia & $16,6^{b}$ & 0,0 & 0,0 & 0,0 & 0,0 \\
\hline Amônia + glutaraldeído & $966,0^{a}$ & 0,0 & 2,7 & 0,0 & 0,0 \\
\hline Clorexidina & $16,8^{b}$ & 0,0 & 0,0 & 0,0 & 0,0 \\
\hline Fenol sintético & $501,8^{a b}$ & 0,0 & 8,8 & 0,0 & 0,0 \\
\hline Formaldeído & $3,8^{\mathrm{b}}$ & 0,0 & 0,0 & 0,0 & 0,0 \\
\hline $\mathrm{P}=$ & 0,007 & 1,000 & 0,501 & 1,000 & 1,000 \\
\hline Média & 223,4 & 0,0 & 4,1 & 0,0 & 0,0 \\
\hline $\mathrm{CV}, \%$ & 255,74 & 0,0 & 452,75 & 0,0 & 0,0 \\
\hline
\end{tabular}

Médias seguidas de letras diferentes na mesma coluna diferem entre si pelo teste de Tukey a 5\% de significância.

Ciência Rural, v.38, n.5, ago, 2008. 
Tabela 2 - Mortalidade embrionária, ovos contaminados, impróprios e eclodibilidade dos ovos submetidos à desinfecção por pulverização com diferentes princípios ativos antes da incubação (experimento 1), \%.

\begin{tabular}{|c|c|c|c|c|c|c|c|}
\hline \multirow{2}{*}{ Tratamentos } & \multicolumn{4}{|c|}{ 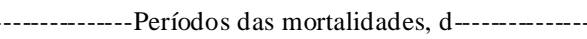 } & \multirow{2}{*}{ Contaminados } & \multirow{2}{*}{ Impróprios ${ }^{1}$} & \multirow{2}{*}{ Eclodibilidade $^{2}$} \\
\hline & $1-3$ & $4-7$ & 8-14 & $15-21$ & & & \\
\hline Controle & 2,8 & 0,8 & 0,4 & 1,4 & 0,0 & 0,2 & 94,1 \\
\hline Amônia & 1,7 & 0,3 & 0,3 & 2,0 & 0,4 & 0,0 & 94,8 \\
\hline Amônia + uréia & 1,8 & 1,1 & 0,8 & 1,3 & 1,0 & 0,0 & 93,4 \\
\hline Amônia + glutaraldeído & 1,6 & 0,8 & 0,5 & 2,7 & 0,4 & 0,2 & 93,3 \\
\hline Clorexidina & 1,5 & 1,0 & 0,1 & 1,8 & 0,2 & 0,0 & 94,9 \\
\hline Fenol sintético & 2,1 & 0,8 & 0,3 & 1,6 & 0,3 & 0,2 & 93,9 \\
\hline Formaldeído & 2,1 & 1,4 & 1,1 & 0,8 & 0,4 & 0,0 & 93,4 \\
\hline $\mathrm{P} \leq$ & 0,771 & 0,588 & 0,698 & 0,409 & 0,394 & 0,562 & 0,868 \\
\hline Média & 1,9 & 0,9 & 0,5 & 1,7 & 0,4 & 0,0 & 94,0 \\
\hline $\mathrm{CV}, \%$ & 14,49 & 10,79 & 10,50 & 13,92 & 9,08 & 4,08 & 3,68 \\
\hline
\end{tabular}

Médias seguidas de letras diferentes na mesma coluna diferem entre si pelo teste de Tukey a 5\% de significância. Foi feita transformação para arco seno sendo mantidas as médias dos tratamentos em \% $(n=40)$.

${ }^{1}$ Não-aptos à criação, com umbigos não-cicatrizados, bicos cruzados, vísceras expostas, problemas locomotores, deficiência de empenamento ou cegos, \%.

${ }^{2}$ Valores expressos sobre os ovos férteis, \%.

submetidos a diferentes princípios desinfetantes aplicados pelo método de pulverização. Não foram detectadas diferenças estatísticas entre tratamentos para nenhuma das variáveis analisadas.

Quando avaliada a prevalência de mesófilos totais, esperava-se maior quantidade de unidades formadoras de colônias (UFC) nos ovos não desinfetados. Entretanto, os resultados obtidos mostram maior contaminação dos ovos desinfetados com a associação entre amônia e glutaraldeído. Este resultado pode ter sido relacionado à quantidade microbiana existente na amostragem. Segundo SCOTT \& GORMAN (1991), a molécula de glutaraldeído tem a capacidade de continuar sua atividade na presença de matéria orgânica, possui amplo espectro e é capaz de destruir todas as formas de vida microbiana, incluindo esporos fúngicos e bacterianos, bacilos e vírus. Contudo, PINHEIRO et al. (1992) submeteram vários desinfetantes à ação de matéria orgânica e verificaram que o glutaraldeído associado com formol e amônia quaternária teve resultado de atuação inferior ao do tratamento com solução desinfetante de hipoclorito de sódio.

Em relação ao resultado obtido pelo grupo tratado com fenol sintético, para mesófilos totais, os resultados ficaram aquém do esperado, pois, segundo O’CONNOR \& RUBINO (1991), este apresenta amplo espectro antimicrobiano sendo bactericida, fungicida, tuberculocida e viricida contra vírus lipofílico, além de apresentar tolerância à água dura e boa atividade residual. SCOTT \& SWETNAM (1993), ao analisarem diversos desinfetantes quanto à sua capacidade de redução microbiana na casca de ovos, concluíram que os desinfetantes à base de compostos fenólicos não tiveram a mesma eficácia se comparados ao formol, corroborando o resultado do presente experimento. DONASSOLO \& NETO (2004), ao avaliar eclodibilidade, mortalidade embrionária e contaminação microbiológica da casca de ovos desinfetados por imersão em solução à base de compostos fenólicos, encontraram resultados superiores ao grupo desinfetado com formaldeído por fumigação. SCOTT \& SWETNAM (1993), todavia, ao compararem redução microbiológica na casca de ovos incubáveis submetidos a diversas soluções desinfetantes encontraram, no grupo desinfetado com glutaraldeído, redução semelhante aos grupos desinfetados com formaldeído, fenóis, clorexidina e amônia quaternária entre outros, confrontando o resultado do trabalho de DAVIDSON et al. (1996) e o resultado obtido neste trabalho.

\section{Experimento 2}

Na tabela 3 podem ser observados os níveis de contaminação por diferentes microrganismos em ovos submetidos a diferentes desinfetantes aplicados pelo método de imersão. O grupo controle evidenciou níveis de contaminação mais elevados, diferindo estatisticamente de todos os outros quando se considerou a contagem de mesófilos totais. Quando considerada a contaminação por coliformes totais, o tratamento controle também diferiu estatisticamente de todos os outros, à exceção do tratamento à base de amônia quaternária associada à uréia, sendo este último semelhante a todos os tratamentos.

Na tabela 4 são apresentados os resultados do embriodiagnóstico dos ovos não eclodidos

Ciência Rural, v.38, n.5, ago, 2008. 
Tabela 3 - Análise microbiológica das cascas de ovos submetidos à desinfecção por imersão com diferentes princípios ativos antes da incubação (experimento 2).

\begin{tabular}{|c|c|c|c|c|c|}
\hline \multirow{2}{*}{ Tratamentos } & \multicolumn{5}{|c|}{ 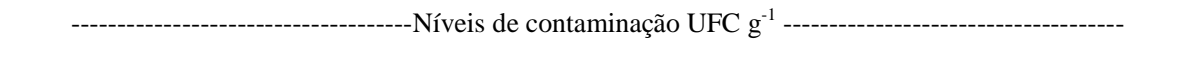 } \\
\hline & Mesófilos totais & Bolores e leveduras & Coliformes totais & Pseudomonas sp & Aspergillus sp \\
\hline Controle & $758,8^{a}$ & 52,0 & $111,2^{a}$ & 0,0 & 0,0 \\
\hline Amônia & $12,0^{b}$ & 10,8 & $0,0^{\mathrm{b}}$ & 0,0 & 0,0 \\
\hline Amônia + uréia & $118,9^{b}$ & 1,7 & $8,3^{\mathrm{ab}}$ & 0,3 & 0,0 \\
\hline Amônia + glutaraldeído & $155,5^{b}$ & 68,2 & $0,0^{\mathrm{b}}$ & 0,0 & 0,0 \\
\hline Clorexidina & $217,0^{b}$ & 1,4 & $0,0^{\mathrm{b}}$ & 0,0 & 0,0 \\
\hline Fenol sintético & $136,6^{b}$ & 7,6 & $0,0^{\mathrm{b}}$ & 0,0 & 0,8 \\
\hline Formaldeído & $58,1^{\mathrm{b}}$ & 70,9 & $0,0^{\mathrm{b}}$ & 0,0 & 0,7 \\
\hline $\mathrm{P}$ ? & 0,002 & 0,079 & 0,016 & 0,436 & 0,117 \\
\hline Média & 208,1 & 30,4 & 17,0 & 0,0 & 0,2 \\
\hline $\mathrm{CV}, \%$ & 166,26 & 208,22 & 403,69 & 748,33 & 360,80 \\
\hline
\end{tabular}

Médias seguidas de letras diferentes na mesma coluna diferem entre si pelo teste de Tukey a 5\% de significância.

submetidos a diferentes princípios desinfetantes aplicados pelo método de imersão. Existiram diferenças significativas somente entre os tratamentos para a mortalidade embrionária entre quatro e sete dias de idade, sendo que a amônia apresentou menor e o fomaldeído maior mortalidade, enquanto que os demais tratamentos foram similares. Quando comparadas as variáveis mortalidade de oito a 14 e de 15 a 16 dias, ovos contaminados, pintos impróprios à criação e eclodibilidade dos ovos férteis, não foi detectada diferença estatística entre os tratamentos.

A baixa eficiência da associação entre amônia e uréia sobre os coliformes totais encontrada neste estudo pode ser explicada pela fraca atuação dos compostos quaternários de amônia frente à matéria orgânica (DEMASI, 1991). Quando analisada, com o dobro da dosagem, a amônia apresentou resultados satisfatórios, apesar de ser bactericida, fungicida, e viricida em concentrações de apenas 10 a 50ppm (MERIANOS, 1991), bem inferiores aos 400ppm utilizados no tratamento em questão. Ao imergirem ovos contaminados artificialmente com Salmonella enteritidis em soluções de cloro e amônia quaternária, OLIVEIRA \& SILVA(2000) verificaram que a amônia foi mais eficiente que o cloro tanto para redução dos níveis de Salmonella quanto de mesófilos totais, de certa

Tabela 4 - Mortalidade embrionária, ovos contaminados, impróprios e eclodibilidade dos ovos submetidos à desinfecção por imersão dom diferentes princípios ativos antes da incubação (experimento 2), \%.

\begin{tabular}{|c|c|c|c|c|c|c|c|}
\hline \multirow{2}{*}{ Tratamentos } & \multicolumn{4}{|c|}{---------Períodos das mortalidades, d--------- } & \multirow{2}{*}{ Contaminados } & \multirow{2}{*}{ Impróprios $^{1}$} & \multirow{2}{*}{ Eclodibilidade $^{2}$} \\
\hline & $1-3$ & $4-7$ & $8-14$ & $15-21$ & & & \\
\hline Controle & 2,1 & $1,4^{\mathrm{ab}}$ & 0,1 & 3,5 & 0,1 & 0,6 & 91,8 \\
\hline Amônia & 1,1 & $0,1^{\mathrm{b}}$ & 0,2 & 4,2 & 0,4 & 0,1 & 93,5 \\
\hline Amônia + uréia & 2,2 & $0,6^{\mathrm{ab}}$ & 0,1 & 4,1 & 0,4 & 0,2 & 92,0 \\
\hline Amônia + glutaraldeído & 1,4 & $0,6^{\mathrm{ab}}$ & 0,6 & 2,6 & 0,9 & 0,8 & 92,7 \\
\hline Clorexidina & 1,6 & $1,7^{\mathrm{ab}}$ & 0,8 & 4,3 & 0,2 & 0,4 & 90,7 \\
\hline Fenol sintético & 2,5 & $0,5^{a b}$ & 0,2 & 5,2 & 1,3 & 0,6 & 89,4 \\
\hline Formaldeído & 1,2 & $1,9^{\mathrm{a}}$ & 0,6 & 2,3 & 0,3 & 0,2 & 93,1 \\
\hline $\mathrm{P} \leq$ & 0,713 & 0,038 & 0,567 & 0,061 & 0,067 & 0,781 & 0,346 \\
\hline Média & 1,7 & 1,0 & 0,4 & 3,7 & 0,5 & 0,4 & 91,9 \\
\hline $\mathrm{CV}, \%$ & 15,79 & 11,38 & 8,97 & 13,42 & 8,53 & 9,41 & 4,86 \\
\hline
\end{tabular}

Médias seguidas de letras diferentes na mesma coluna diferem entre si pelo teste de Tukey a 5\% de significância. Foi feita transformação para arco seno sendo mantidas as médias dos tratamentos em \% $(n=40)$.

${ }^{1}$ Não-aptos à criação, com umbigos não-cicatrizados, bicos cruzados, vísceras expostas, problemas locomotores, deficiência de empenamento ou cegos, \%.

${ }^{2}$ Valores expressos sobre os ovos férteis, \%.

Ciência Rural, v.38, n.5, ago, 2008. 
forma contrariando os resultados obtidos neste trabalho. BRAKE \& SHELDON (1990), por sua vez, avaliaram a contagem microbiológica da casca dos ovos pulverizados contra um grupo controle e verificaram que a redução bacteriana foi de $98 \%$ após a pulverização com amônia quaternária, contrapondo também os resultados encontrados neste trabalho. Da mesma forma, SACCO et al. (1989) compararam fumigação com formol e desinfecção com amônia quaternária a fim de verificar a redução bacteriana na casca e na gema de ovos pós-desinfecção e não encontraram diferenças entre os tratamentos.

SHELDON \& BRAKE (1991) avaliaram eclodibilidade, mortalidade de um a sete e de oito a 20 dias em ovos desinfetados por meio de fumigação com formaldeído, comparados a um grupo pulverizado com peróxido de hidrogênio e outro grupo pulverizado com água estéril. Estes autores detectaram diferenças na mortalidade de oito a 20 dias, constatando maior mortalidade no grupo tratado com formaldeído, confrontando os resultados obtidos neste experimento. JáWHISTLER \& SHELDON(1989)conduziramum estudo em que foram comparadas as fumigações com formaldeído e com ozônio. Avaliando a eclodibilidade dos ovos férteis, os autores detectaram diferença significativa, sendo o grupo tratado com formaldeído superior, com maior eclodibilidade de ovos férteis (89,4\%), se comparado ao grupo tratado com ozônio (50\%), ou seja, não constataram perdas de produtividade relacionadas ao uso de formaldeído, assim como neste estudo.

\section{CONCLUSÕES}

De modo geral, a utilização de soluções desinfetantes para desinfecção da casca dos ovos nos momentos subseqüentes à postura por meio dos métodos de pulverização e imersão inibiu o desenvolvimento de microrganismos sem afetar negativamente o desenvolvimento embrionário. Dessa forma, todas as soluções desinfetantes testadas podem ser recomendadas para uso, sem grandes restrições.

\section{REFERÊNCIAS}

BRAKE, J.; SHELDON, B.W. Effect of a quaternary ammonium sanitizer for hatching eggs on their contamination, permeability, water loss, and hatchability. Poultry Science, v.69, p.517525, 1990.

DAVIDSON, S. et al. Evaluation of disinfectants against Salmonella enteritidis. Avian Diseases. v.40, p.272-277, 1996.

DEMASI, M. Anti-sépticos, desinfetantes, esterilizantes. In: VALE, L.B.S. et al. Farmacologia integrada, fundamentos farmacológicos da terapêutica. São Paulo: Ateneu, 1991. V.2, p.576-606.
DONASSOLO, E.; NETO, G.C.C. Ação do fenol sintético e do aldeído fórmico na proteção de embriões de Gallus gallus para fins comerciais. 2004. 48f. Monografia (Trabalho de Conclusão do Curso de Ciências Biológicas) Universidade Paranaense, Cascavel.

MAPA. Manual de métodos analíticos oficiais para análise microbiológica para controle de produtos de origem animal e água. Brasília: Diário Oficial da União, Instrução Normativa $n^{\underline{0}} 62$, de 26 de agosto de 2003.

MAULDIN, J.M. Maintaining hatching egg quality. In: BELL, D.D.; WEAVER, W.D. Commercial chicken meat and egg production. 5.ed. Norwell: Kluwer Academic, 2002. p.707725 .

McQUOID, D. Operation of multiple-stage and single-stage incubation systems. World Poultry, v.2, p.5-7, 2000.

MERIANOS, J.J. Quaternary ammonium antimicrobial compounds. In: BLOCK, S.S. Disinfection, sterilization and preservation. 4.ed. Philadelphia: Lea \& Febiger, 1991. p. 225-255.

O’CONNOR, D.O.; RUBINO, J.R. Phenolic compounds. In: BLOCK, S.S. Disinfection, sterilization and preservation. 4.ed. Philadelphia: Lea \& Febiger, 1991. p.204-224.

OLIVEIRA, D.D.; SILVA, E.N. Salmonella em ovos comerciais: ocorrência, condições de armazenamento e desinfecção da casca. Arquivo Brasileiro de Medicina Veterinária e Zootecnia, v.52, n.6, p.655-661, 2000.

PINHEIRO, S.R. et al. Influência da matéria orgânica na atividade micobactericida de cinco desinfetantes químicos de uso pecuário. Brazilian Journal of Vetetinary Research and Animal Science, v.29, n.1, p.51-60, 1992.

PROUDFOOT, F.G. et al. Effects of glutaraldehyde-surfactant solution on the hatchability of the hen's eggs. Poultry Science, v.64, p.2400-2402, 1985.

SACCO, R.E. et al. Effect of hatching egg sanitizers on embryonic survival and hatchability of turkey eggs from different lines and on eggs shell bacterial populations. Poultry Science, v.68, p.1179-1184, 1989.

SCOTT, E.M.; GORMAN, S.P. Glutaraldehyde. In: BLOCK, S.S. Disinfection, sterilization and preservation. 4.ed. Philadelphia: Lea \& Febiger, 1991. p.596-614.

SCOTT, T.A.; SWETNAM, C. Screening sanitizing agents and methods of application for hatching eggs. II. Effectiveness against microorganisms on the egg shell. Journal Applied Poultry Research, v.2, p.7-11, 1993.

SESTI, L.A.C. Biosseguridade em granjas de reprodutoras. In: MACARI, M.; MENDES, A.A. Manejo de matrizes de corte. Santos: Facta, 2005. p.244-317.

SHELDON, B.W.; BRAKE, J. Hydrogen peroxide as an alternative hatching egg disinfectant. Poultry Science, v.70, p.1092-1098, 1991.

WHISTLER, P.E.; SHELDON, B.W. Bactericidal activity, eggshell conductance, and hatchability effects of ozone versus formaldehyde disinfection. Poultry Science, v.68, p.10741077, 1989. 